\title{
Ethoxylated Amine Friction Modifiers and ZDDP
}

\author{
Joanna Dawczyk ${ }^{1} \cdot$ Joe Russo $^{2} \cdot$ Hugh Spikes $^{1}$ (i) \\ Received: 4 April 2019 / Accepted: 31 August 2019 / Published online: 13 September 2019 \\ (C) The Author(s) 2019
}

\begin{abstract}
The influence of a series of Ethomeens (ethoxylated alkylamine organic friction modifiers) on the durability and friction of tribofilms formed by a commercial blend of primary and secondary ZDDP in sliding/rolling contact has been studied. When pre-formed ZDDP tribofilms are rubbed in Ethomeen solution, boundary friction is reduced and some of the ZDDP film is removed. Ethomeens having just two ethoxy groups give lower boundary friction on ZDDP than those with 15 ethoxy groups, but result in much greater removal of the tribofilm itself. Based on XANES analysis, the film removed by both types of Ethomeen consists primarily of nanocrystalline orthophosphate. The level of boundary friction and its dependence on sliding speed, coupled with the dimensions of the molecules, suggests that the Ethomeens with two ethoxy groups may form quite closely packed vertical monolayers on ZDDP tribofilm surfaces, but that those with fifteen ethoxy groups cannot be close packed; yet they still reduce boundary friction significantly. The study shows that selection of an appropriate aminic friction modifier for use with ZDDP is a balance between its ability to reduce friction and its potentially harmful effect on a ZDDP tribofilm.
\end{abstract}

Keywords Organic friction modifier $\cdot$ OFM $\cdot$ Ethomeen $\cdot$ ZDDP $\cdot$ Boundary friction

\section{Introduction}

Zinc dialkyl- and diaryldithiophosphates (ZDDP) are used as antiwear and extreme pressure additives in almost all current crankcase engine oils. They react in rubbing contacts to form inorganic tribofilms consisting primarily of zinc orthophosphate and polyphosphate. When formed in macro-scale rubbing contact, these films are typically 30 to $150 \mathrm{~nm}$ thick and have a characteristic pad-like structure, with an array of pads of ca 2 to $6 \mu \mathrm{m}$ diameter separated by deep valleys, as illustrated in the AFM topography image in Fig. 1 which shows a ZDDP tribofilm formed in this study.

Although very effective in preventing wear, ZDDP films can result in an increase in friction and this can reduce engine fuel economy $[1,2]$. One way to address this problem is to combine the use of ZDDPs with suitable friction modifier additives that reduce friction in thin-film conditions. Previous work has shown that some currently used friction modifiers can be effective in this fashion but that

\footnotetext{
Hugh Spikes

h.spikes@imperial.ac.uk

Imperial College London, London, UK

2 Shell Global Solutions, Houston, TX, USA
}

others are relatively ineffective [3]. It has also been found that some friction modifiers, in particular primary amines, while reducing boundary friction also severely damage ZDDP tribofilms and in some cases destroy them entirely [3].

This paper explores the impact of one widely used family of commercial organic friction modifiers (OFMs) on ZDDP tribofilms, both in terms of their ability to reduce friction and their impact on tribofilm thickness. The OFMs studied, the Ethomeens, are based on tertiary substituted amines and are available in a range of different structures, enabling the impact of molecular structure on behaviour to be explored systematically.

\section{Background}

It is well known that the presence of ZDDP in engine oils can lead to a reduction in engine fuel economy $[1,4]$ and that this results from an increase in friction [2]. However, the precise way that ZDDP increases friction is complex. Initially, it was supposed that the sliding interface between ZDDP tribofilms on opposing surfaces had high shear strength and thus high boundary friction. Then in 1996 it 


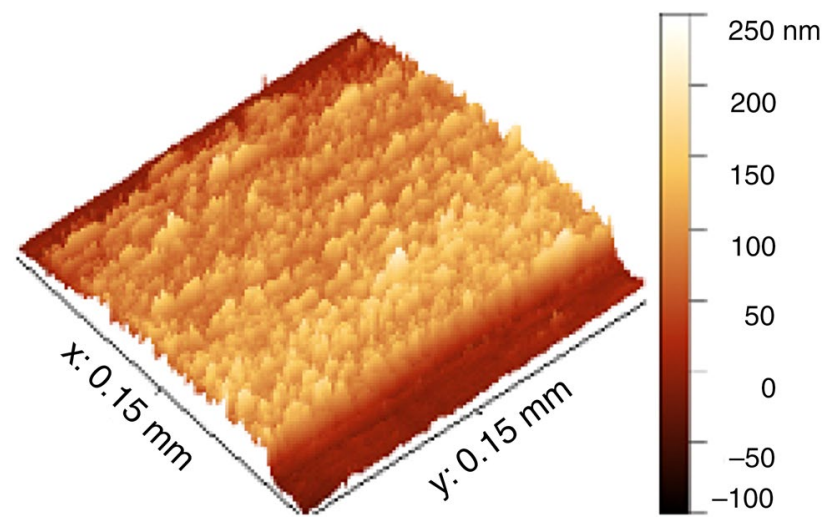

Fig. 1 AFM of typical ZDDP tribofilm from unidirectional MTM rolling-sliding test

was shown that when ZDDP films were formed on rubbed surfaces, a higher entrainment speed was required to separate the surfaces and develop a hydrodynamic film [5]. This means that the contact remained in boundary or mixed film lubrication, with consequently high friction, up to higher entrainment speeds than in the absence of a ZDDP film. Various reasons for this behaviour have been suggested but very recently it has been shown that it arises primarily because of the increase in surface roughness of the surfaces due to formation of a rough, solid tribofilm [6]. Clearly complete separation of the rubbing solid surfaces can only occur, and thus full EHD lubrication conditions be reached, when sufficient lubricant is entrained to form a hydrodynamic film that is thicker than the height of the surface roughness features, and the rougher the surface, the higher the required entrainment speed.

Since ZDDP tribofilms increase the proportion of time that lubricated components spend in mixed and boundary lubrication conditions, their boundary friction properties are of considerable importance. Using a cylinder on ring sliding contact, Aoki et al. showed that secondary ZDDPs gave higher boundary friction than primary ones based on linear alkyl groups. Also, ZDDPs with longer, linear alkyl groups gave lower boundary friction than those based on shorter chains [7]. Hoshino et al. used a rolling-sliding contact to compare the friction properties of three ZDDPs, two primaries, linear $n$-octyl and branched 2-ethylhexyl, and a secondary ZDDP based on 4-methylpent-2-yl [8]. They showed that boundary friction varied in the order octyl < ethylhexyl < methylpentyl. Also the ZDDP with linear alkyl groups showed friction that increased linearly with $\log$ (sliding speed), a phenomenon generally seen with effective organic friction modifiers [9]. These studies were made with simple solutions of ZDDP in base oil, suggesting that the observed boundary friction dependence probably resulted from the alkyl groups of partially alkylated phosphate at the outermost surface of the ZDDP tribofilm acting in a similar fashion to an organic friction modifier.

Linear, primary alcohols that produce ZDDPs with the lowest friction cannot, however, be used to prepare secondary ZDDPs, since by definition the latter must have two C atoms attached to the $\alpha$-carbon. An alternative approach to producing low friction with ZDDPs is to reduce the boundary friction coefficient of ZDDP tribofilms using friction modifier additives. The most widely researched such additives are the molybdenum dialkyldithiocarbamates (MoDTC) and it has been found that these are able to produce low-friction boundary films in combination with ZDDP and indeed that ZDDP may enhance the effectiveness of MoDTC [10-17]. It has also been shown that MoDTC does not significantly inhibit ZDDP film formation and can form a low-friction film on top of a pre-formed ZDDP tribofilm [3]. Much less research appears to have been published on the behaviour of OFMs with ZDDP, although there are numerous patents showing that various OFMs are effective in reducing friction in ZDDP-containing oils [e.g. 18-22]. Topolovec et al. studied the impact of a range of OFMs on ZDDP tribofilms using two approaches [3]. In one they used a minitraction machine (MTM) operating in thin-film rolling-sliding conditions to form tribofilms from ZDDP solution and then replaced the ZDDP solution by one of OFM in base oil and monitored the resulting friction and tribofilm thickness. They found that some OFMs were quite ineffective in reducing friction and also had little effect on the ZDDP film. However, others, in particular a linear primary amine, reduced friction but led to most of the ZDDP film being lost from the surface. Glyceryl monooleate (GMO) and oleyl amide were able to reduce boundary friction without resulting in loss of the ZDDP tribofilm. Recently Ratoi has carried out a similar study with similar findings [23]. Topolovec et al. also used the MTM to study the film formation and friction of ZDDP + OFM blends where both additives were present at the outset [3]. They found that the amine and amide inhibited ZDDP tribofilm formation but that GMO reduced the thickness of the ZDDP film only slightly. By contrast, Dobrenizki et al. found that GMO inhibited the formation of a ZDDP tribofilm almost entirely [24]. It is not yet clear whether the OFMs inhibit tribofilm formation by blocking the surface, interacting with ZDDP at the surface or simply by reducing boundary friction and thus the mechanical forces to which ZDDP molecules are subject during their reaction.

Eriksson compared the behaviour of two aminic friction modifiers, a primary amine and also one of the tertiary substituted Ethomeens of interest to the current study [25]. She found that both reduced friction with ZDDP and both inhibited ZDDP tribofilm formation, the primary amine much more than the Ethomeen. Lundgren et al. studied the impact of a primary amine, a dialkyl amine and a trialkyl amine on ZDDP film formation and friction with and 
without MoDTC [26]. They found that the amines alone were able to reduce friction but this effect was boosted by the presence of small concentrations of MoDTC, much lower than the level at which MoDTC is normally effective. They found that both the primary and secondary amines reduced the extent of ZDDP tribofilm formation.

From the above it is clear that some OFMs can help mitigate the impact of ZDDP on increasing friction but that care must be taken in the choice of OFM since some can also inhibit ZDDP film formation or damage pre-formed ZDDP films. Amine-based OFMs are particularly effective OFMs at reducing ZDDP friction, which is perhaps unsurprising since the outermost layer of a ZDDP tribofilm is likely to be based on phosphate and thus be acidic. However, primary amines are very damaging to ZDDP films, possibly because the amine groups chelate $\mathrm{Zn}^{2+}$ ions from the ZDDP film [3]. Secondary and especially tertiary amines appear somewhat less effective at reducing friction but much less harmful to ZDDP films, perhaps because the nitrogen atom that may interact with ZDDP tribofilm is sterically hindered. This paper explores the effectiveness of a range of tertiary amines in terms of this balance.

As described by Topolovec et al. [3], the impact of OFMs on ZDDP behaviour can be studied in two ways: (i) by examining the effect of OFMs on the film formation rate and friction of ZDDP-containing oils using blends containing both additives or (ii) by studying the effect of OFMs on the friction and durability of pre-formed tribofilms. In this paper, the latter approach is used. This has practical relevance when engines are run in using OFMfree factory fill oils but OFM-based oils are subsequently employed.

\section{Materials}

The base fluid employed was a group II mineral oil containing a non-functionalised olefin copolymer viscosity modifier additive. This combination of base oil and viscosity index improver was typical of the base fluid blend used in formulating modern gasoline engine oils. The base blend had VI 167 and dynamic viscosity $7.53 \mathrm{mPas}$ at $100{ }^{\circ} \mathrm{C}$.

One commercial ZDDP was employed, at a concentration of $0.08 \mathrm{wt} \%$ P. This was a blend of $67 \%$ C6 secondary ZDDP and $33 \% \mathrm{C} 8$ primary ZDDP and was $76 \%$ neutral.

The OFMs studied were some of the family of commercial polyethoxyalkylated tertiary amines with generic name Ethomeens [27]. The core of these Ethomeens is a tertiary nitrogen atom. This carries three groups: one alkyl or alkenyl group and two ethoxy groups or polyethoxy chains. Six Ethomeens were investigated, as listed in Table 1. These have two ethoxy groups each consisting of single ethoxy-OH species (denoted/12) or a pair of polyethoxy chains terminating in an alcohol such that there are 15 ethoxy groups in total (denoted/25).

Ethomeens with three different alkyl/alkenyl types were used in this study; one with predominantly linear, saturated octadecyl-groups (denoted 18/), one with a mixture of alkyl groups derived from coconut oil (denoted $\mathrm{C} /$ ), and one a mixture of alkyl groups originating from tallow (denoted $\mathrm{T} /$ ). The coconut-derived alkyl chains were predominantly saturated, while the tallow-derived alkyls had a significant unsaturated component. The representative alkyl composition for each Ethomeen type is listed in Table 2. In this table, a single apostrophe indicates one $\mathrm{C}=\mathrm{C}$ double bond per molecule; two apostrophes indicates two $\mathrm{C}=\mathrm{C}$ double bonds. All Ethomeens were used at a concentration of $1.0 \mathrm{wt} \%$ in base blend.

Figure 2 shows representative structures of three of the Ethomeens studied to illustrate the types of structural component present.

\section{Test Methods}

\subsection{MTM-SLIM}

A Mini Traction Machine with Spacer Layer Imaging (MTM-SLIM) was used to study the influence of OFMs on pre-formed ZDDP tribofilm thickness and friction. In the

Table 1 Ethomeens studied

\begin{tabular}{|c|c|c|c|c|}
\hline Commercial name & Predominant alkyl group & Saturation level & $\begin{array}{l}\text { Number of ethoxy } \\
\text { groups }\end{array}$ & Code of solution \\
\hline Ethomeen $18 / 12$ & 18 (sat.) & Saturated & 2 & $18 / 12$ \\
\hline Ethomeen $18 / 25$ & 18 (sat.) & Saturated & 15 & $18 / 25$ \\
\hline Ethomeen $\mathrm{C} / 12$ & 12 and 14 (sat.) & Saturated & 2 & $\mathrm{C} / 12$ \\
\hline Ethomeen $\mathrm{C} / 25$ & 12 and 14 (sat.) & Saturated & 15 & $\mathrm{C} / 25$ \\
\hline Ethomeen $\mathrm{T} / 12$ & 18 (unsat.) & Mixed saturated and unsaturated & 2 & $\mathrm{~T} / 12$ \\
\hline Ethomeen $\mathrm{T} / 25$ & 18 (unsat.) & Mixed saturated and unsaturated & 15 & $\mathrm{~T} / 25$ \\
\hline
\end{tabular}


Table 2 Approximate alkyl group distribution in Ethomeens [27]

\begin{tabular}{llll}
\hline $\begin{array}{l}\text { Chain length and } \\
\text { saturation }\end{array}$ & $\begin{array}{l}\text { Ethomeen T/ } \\
\text { (Tallow) } \%)\end{array}$ & $\begin{array}{l}\text { Ethomeen C/ } \\
(\text { Coco) }(\%)\end{array}$ & $\begin{array}{l}\text { Ethomeen 18/ } \\
\text { (Octadecyl) } \\
(\%)\end{array}$ \\
\hline $\begin{array}{l}\text { Saturated } \\
\text { C8 }\end{array}$ & 0 & & \\
C9 & 0 & 6 & 0 \\
C10 & 0 & 0 & 0 \\
C11 & 0 & 7 & 0 \\
C12 & 0 & 0 & 0 \\
C13 & 0 & 51 & 0 \\
C14 & 3 & 0 & 0 \\
C15 & 0.5 & 19 & 0 \\
C16 & 29 & 0 & 0 \\
C17 & 1 & 9 & 2.5 \\
C18 & 20 & 0 & 0 \\
C19 & 0 & 2 & 96.5 \\
C20 & 0 & 0 & 0 \\
1 double bond & & 0 & 0.5 \\
C14' & 0.5 & 0 & 0 \\
C16' & 2.0 & 0 & 0 \\
C18' & 44.0 & 0 & 0 \\
2 double bonds & & 6 & 0 \\
C18" & 0 & 0 & \\
Total & 100 & & 0 \\
\hline
\end{tabular}

MTM, a lubricated steel ball and disc are rubbed together in mixed sliding-rolling at a controlled load and temperature while friction is monitored.

The Spacer Layer Imaging Method (SLIM) allows in situ measurement of sub-micron thick tribofilms formed on rubbed steel balls in the MTM. The principles of SLIM, which is based on optical interferometry, are shown in Fig. 3. For a SLIM measurement, rotation of the 19-mm-diameter steel test ball is halted and it is uploaded against a coated glass mapper disc. White light is shone into the resulting contact where some is reflected by a semi-reflective coating on the underside of the glass, while the remainder passes through a silica spacer layer and any tribofilm on the ball before being reflected back from the steel substrate. The two beams undergo optical interference depending on their optical path difference and thus on the antiwear film thickness. The result is an interference image as shown in Fig. 3, which is captured as a RGB pixel map by a high-resolution camera. A calibration chart of RGB colour versus optical path difference obtained using ultrathin-film interferometry is then used to convert this RGB pixel map to a ZDDP tribofilm thickness map [28]. A refractive index of 1.6 was assumed for the ZDDP tribofilm [29]. The advantage of SLIM is that tribofilm thickness is measured in situ without rinsing or cooling the MTM ball or removing it from the test rig. It should be noted, however, that the film average thickness measured is a value closer to the maximum than the mean film thickness since the glass disc does not fully conform to the rough ZDDP tribofilm [6].

In the current study, AISI 52100 steel balls and discs were used with hardness ca $840 \mathrm{Hv}$. These were ultrasonically cleaned successively in toluene and Analar isopropanol for $10 \mathrm{~min}$ prior to use.

The test sequence used in this study consisted of two stages: stage 1 to form a ZDDP tribofilm and stage 2 to observe the impact of an OFM on this film.

At the start of stage 1, an initial SLIM interference image was taken before any rubbing commenced to determine the spacer layer thickness. Then the ball and disc were rubbed together in low entrainment speed (and thus thin EHD film), sliding-rolling conditions for $3 \mathrm{~h}$ to generate a ZDDP tribofilm on the ball and disc. At this low entrainment speed, the theoretical EHD film thickness based on the Dowson and Chittenden equation $[30,31]$ was $5.5 \mathrm{~nm}$. This corresponds to a lambda ratio (ratio of EHD film thickness to composite surface roughness) of 0.5 , indicating considerable asperity contact and thus mixed lubrication conditions. Periodically during these $3 \mathrm{~h}$ (after 3, 6, 15, 30, 60, 120 and 180 min rubbing), rolling-sliding was halted and a film thickness map and a friction curve were obtained. Immediately after motion was halted, the ball was uploaded against a coated glass window and SLIM used to capture an interference image of the tribofilm and thus a film thickness map. This was followed by acquisition of a friction versus entrainment speed Stribeck curve in which friction was measured as entrainment speed (and thus EHD film thickness) was progressively decreased from a high to a low value at a fixed slide-to-roll ratio.

At the end of stage 1, the ZDDP-containing oil was drained from the test rig and any residues blown out with a heat gun. An OFM test solution was then added to the MTM pot and a rubbing test identical to stage 1 above (except that the first SLIM image obtained was that of ZDDP film) was carried out.

Test conditions are summarised in Table 3.

\subsection{Atomic Force Microscopy (AFM)}

AFM was used to characterise the thickness and roughness of the ZDDP tribofilms present. A confocal AFM-Raman alpha300 RA produced by WiTec was employed in contact mode. At the end of an MTM test, the disc specimen was rinsed with heptane. The specimen was then dried and a drop of 0.05 M EDTA solution was placed to cover half the width of part of the wear track, and wiped off after $60 \mathrm{~s}$ [32]. This treatment removes the ZDDP tribofilm entirely to reveal the steel substrate and was done for two reasons. Firstly, a single AFM image was not able to map the 
Fig. 2 Representative structures of Ethomeen 18/12, 18/25 and $\mathrm{T} / 25$
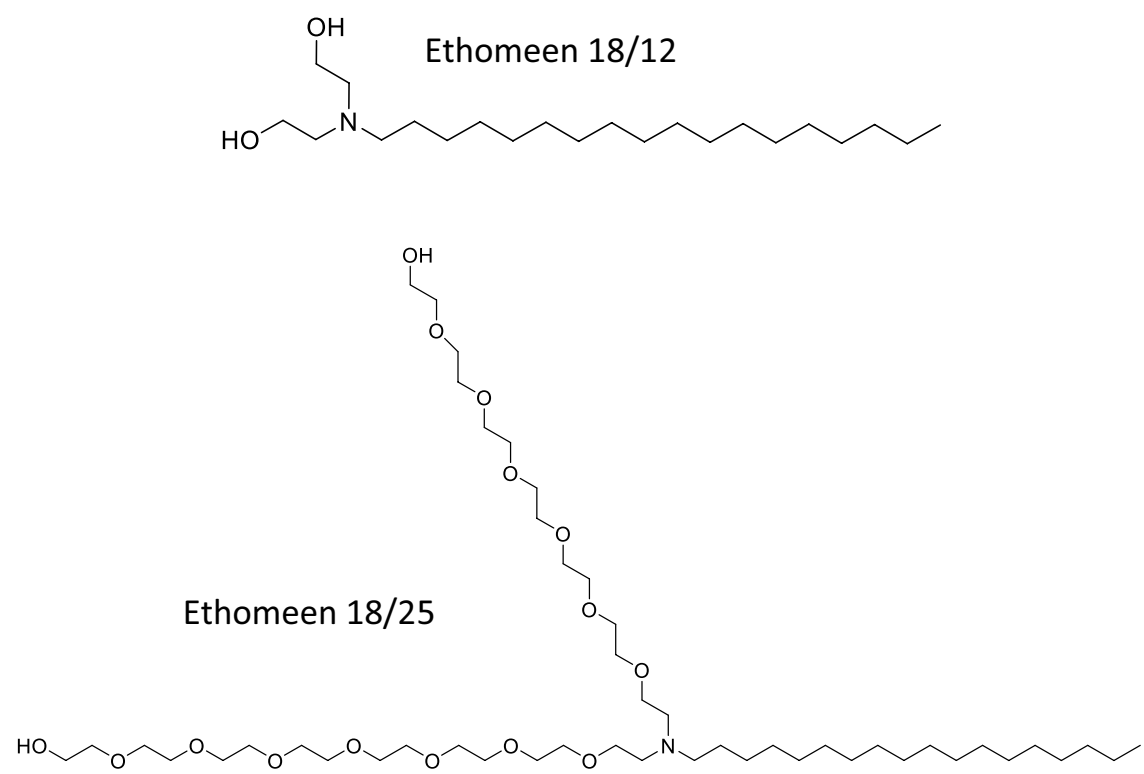

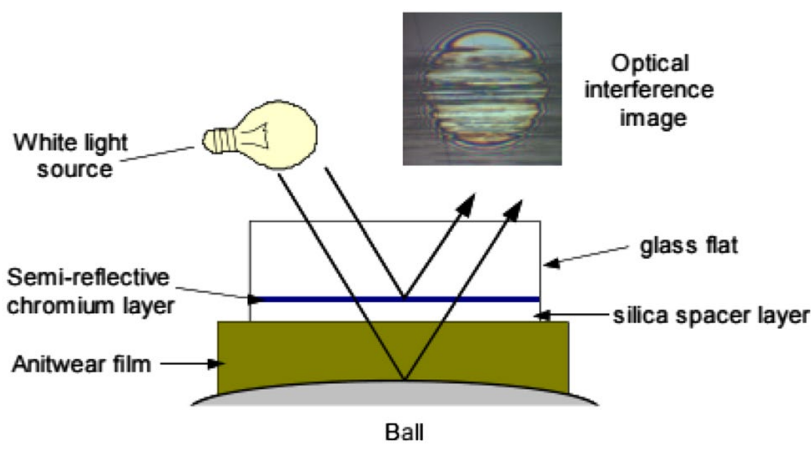

Fig. 3 The principles of spacer layer interferometry method (SLIM)
Table 3 Conditions of MTM test (stages 1 and 2)

\begin{tabular}{lrlr}
\hline & $\begin{array}{l}\text { Slow- } \\
\text { speed } \\
\text { rubbing }\end{array}$ & Stribeck curve acquisition \\
& 180 & - & 50 \\
Total duration (min) & 50 & & 31 \\
Slide-to-roll ratio (SRR) (\%) & 31 & & Decreasing from 3500 to 7 \\
Ball load (N) & 50 & 100 \\
Entrainment speed (mm/s) & 100 & \\
Temperature $\left({ }^{\circ} \mathrm{C}\right)$ & &
\end{tabular}

on either side, as shown in Fig. 4. Secondly, it provided a check as to whether any wear had taken place beneath the ZDDP tribofilm.

topography of the whole $300 \mu \mathrm{m}$ wide rubbed track, but by reducing the width of the ZDDP film by half an AFM topography map could be acquired with reference surfaces 
Fig. 4 AFM image of part of tribofilm. The left-hand side of the tribofilm has been removed using EDTA solution to provide a reference plane

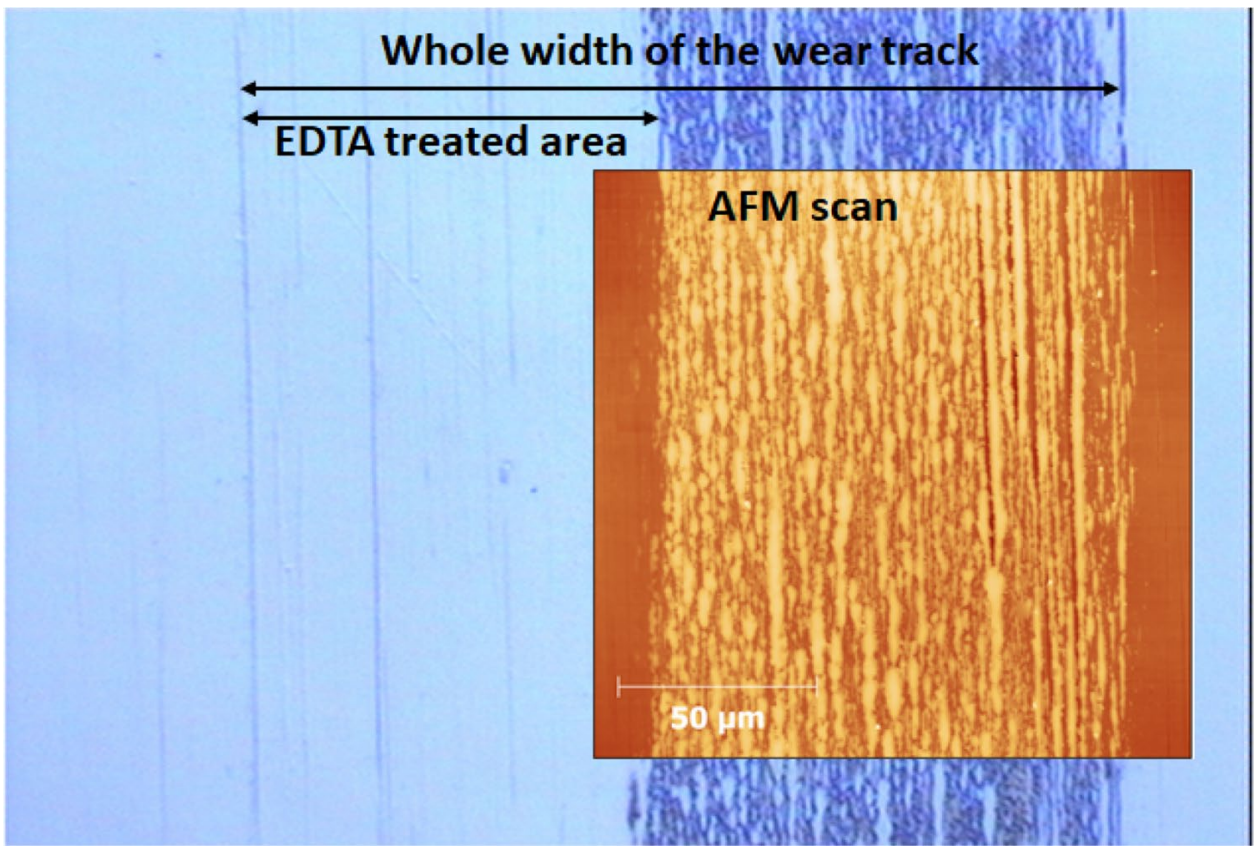

\subsection{Scanning White Light Interferometry (SWLI)}

SWLI was also used to map the topography and thickness of ZDDP tribofilms. An SWLI microscope (Wyko NT9100) was employed in vertical scanning interferometry (VSI) mode. SWLI has the advantage of being able to measure films easily on both the MTM ball and disc surfaces. AFM measurements from MTM balls are possible but their curvature makes an accurate estimate of the film thickness quite difficult. Another advantage of SWLI is that it can map across the whole width of the rubbed track. SWLI's main disadvantage for studying ZDDP tribofilms is that, as shown by Benedet et al., internal reflections within the transparent tribofilm leads to incorrect measurements [33]. This can be avoided by depositing a thin (ca $25 \mathrm{~nm}$ ) film of gold on the ZDDP tribofilm surface and its surrounds to make it fully reflective.

\subsection{Focused Ion Beam (FIB)-Transmission Electron Microscopy (TEM)}

Focussed ion beam milling was used to cut pairs of vertical slots into rubbed tracks and extract lamellae for TEM and EDX analysis. Prior to FIB, the specimens were cleaned in an ultrasonic bath for $15 \mathrm{~min}$ in toluene and then rinsed in isopropanol. Then the rubbed track to be milled was sputter-coated with a $60-70-\mathrm{nm}$ gold layer to protect it from the high-energy $\mathrm{Ga} / \mathrm{Pt}$ ion beam used in milling. TEM was employed to investigate the structure of the ZDDP film and EDX to map the elemental composition of the lamellae. The process of TEM specimen preparation is fully described in [34].

\subsection{X-ray Absorption Near Edge Structure (XANES)}

X-ray absorption near edge structure (XANES) was employed to investigate the chemical composition of ZDDP tribofilms before and after rubbing in OFM. Two modes were applied: fluorescence yield (FY) and total electron yield (TEY). The results were collected at the Canadian Light Source (CLS, Saskatoon, Canada) on the Variable Line Spacing Plane Grating Monochromator Beamline. The energy ranges were chosen in order to include the binding energies of chemical compounds containing sulphur (S) and phosphorus $(\mathrm{P})$. For chemical compounds containing $\mathrm{S}$, results were collected in energy range $58-193 \mathrm{eV}$, while for chemical compounds containing $\mathrm{P}$, results were collected in energy range of $130-156 \mathrm{eV}$, spanning the $\mathrm{S}$ and $\mathrm{P}$ L-edge transitions. Reference samples are summarised in Table 4. Athena software was used to process the results [35]. For the

Table 4 Reference samples for XANES

\begin{tabular}{ll}
\hline Chemical & Origin \\
\hline Zinc orthophosphate, $\mathrm{Zn}_{3}\left(\mathrm{PO}_{4}\right)_{2}$ & Sigma-Aldrich \\
Zinc pyrophosphate, $\mathrm{Zn}_{2} \mathrm{P}_{2} \mathrm{O}_{7}$ & Rossi, ETH \\
Zinc metaphosphate, $\mathrm{ZnP}_{2} \mathrm{O}_{6}$ & Rossi, ETH \\
Zinc polyphosphate, $\mathrm{Zn}_{4} \mathrm{P}_{6} \mathrm{O}_{19}$ & Rossi, ETH \\
Iron (III) pyrophosphate, $\mathrm{Fe} 4\left(\mathrm{P}_{2} \mathrm{O}_{7}\right)_{3}$ & Sigma-Aldrich \\
Iron (II) sulphide, $\mathrm{FeS}$ & Fischer-Scientific \\
Iron disulphide, $\mathrm{FeS}$ & Alfa Aesar \\
Zinc sulphide, $\mathrm{ZnS}$ & Sigma-Aldrich \\
Iron sulphate, $\mathrm{FeSO}_{4}$ & Sigma-Aldrich \\
Zinc sulphate, $\mathrm{ZnSO}_{4}$ & Sigma-Aldrich \\
\hline
\end{tabular}


L-edge, TEY probes a depth of about $5 \mathrm{~nm}$, while FY probes about $50 \mathrm{~nm}$ [36].

\section{Results}

\subsection{Base Blend: Film Thickness and Friction}

Figure 5 shows two series of SLIM images, the first as the ZDDP film grows in the first 3-h stage of a test using ZDDP solution (stage 1) and the second after the ZDDP solution has been replaced by base blend (BB) without any OFM (stage 2). The first image in each case is from the ball which was immersed in oil but not rubbed. The second is after a Stribeck curve but no low speed rubbing period. The subsequent seven images are of the tribofilm at various times during the 3-h rubbing test (values shown are in minutes). With ZDDP solution, it can be seen that a coloured interference image, as indicated by the brown and then dark blue region in the upper part of the images, develops progressively during rubbing. The contact between ball and glass window is deliberately offset so as to capture some of the rubbed track on the ball together with region outside the track. ZDDP tribofilm forms only in the rubbed track.

Upon replacement by base blend, as shown in the lower set of images some of the outermost film is removed even before any rubbing takes place, but most of the film (corresponding to ca $120 \mathrm{~nm}$ ) remains for $3 \mathrm{~h}$ of rubbing in base blend.

Figure 6 shows friction coefficient versus entrainment speed curves (Stribeck curves) obtained during stage 2 when the ZDDP tribofilm is rubbed in base blend. For clarity, only curves after 3-, 15-, 30- and 180-min rubbing are shown. It is evident that there is very little change either in the level of boundary friction at slow speed or in the overall shape of the friction curves during $3 \mathrm{~h}$ of rubbing in the base fluid. This is consistent with the fact that very little of the ZDDP film is removed.

\subsection{OFM Solutions: Film Thickness and Friction}

Figure 7 shows two sets of SLIM images during stage 2 of two tests, where ZDDP solution was replaced by $18 / 12$ and $18 / 25$ solutions, respectively. For brevity, images from the

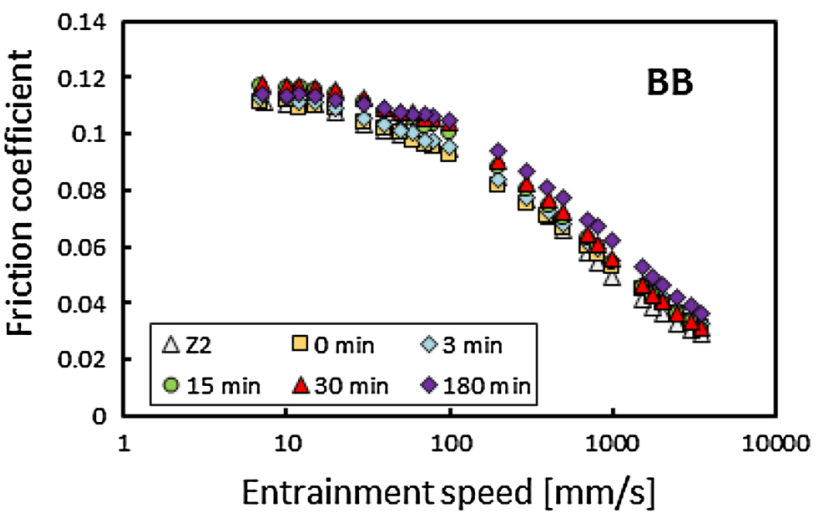

Fig. 6 MTM Stribeck curves obtained during stage 2 using base blend. Z2 is the final MTM friction curve obtained with ZDDP solution in stage 1

preceding stage 1 of these tests, in which the ZDDP tribofilms were developed are omitted. With 18/12, a significant proportion of the film is lost after just one Stribeck curve is taken and the film thickness then reduces considerably during the first $30 \mathrm{~min}$ rubbing. After this no further film is removed. With 18/25 very little if any ZDDP is removed initially, but some of the film starts to be lost after about 30-min rubbing. This film removal appears to occur from the sides of the rubbed track. Figure $8 \mathrm{a}$ and $\mathrm{b}$ shows the corresponding Stribeck curves. Z2 denotes the last Stribeck curve taken in stage 1 , from the ZDDP film after 3-h rubbing. 0 min is the Stribeck curve taken immediately after the ZDDP solution has been replaced by OFM solution. It is clear that both OFMs produce an immediate reduction in boundary friction, with $18 / 12$ giving lower friction than $18 / 25$. The dependence of boundary friction on speed is quite different however, with 18/12 giving friction that increases linearly with $\log$ (entrainment) and thus, at fixed SRR, with $\log$ (sliding speed), while with $18 / 25$ boundary friction is almost independent of sliding speed. With 18/12, while boundary friction at a given sliding speed remains almost constant during slow-speed rubbing, there is a progressive reduction in friction in the mixed lubrication regime. This is indicative of some loss of effective roughness of the film, to promote fluid entrainment. No such effect is seen with 18/25.

To indicate repeatability, Fig. 9 shows friction curves after 180-min rubbing in stage 2 for three repeat tests with
Fig. 5 SLIM images of tribofilm formation during 3-h rubbing in ZDDP solution (stage 1 , upper row) and when ZDDP solution is replaced by base blend and rubbing continued for $3 \mathrm{~h}$ (stage 2, lower row). BB is base blend, i.e. the base oil and VM blend without any ZDDP

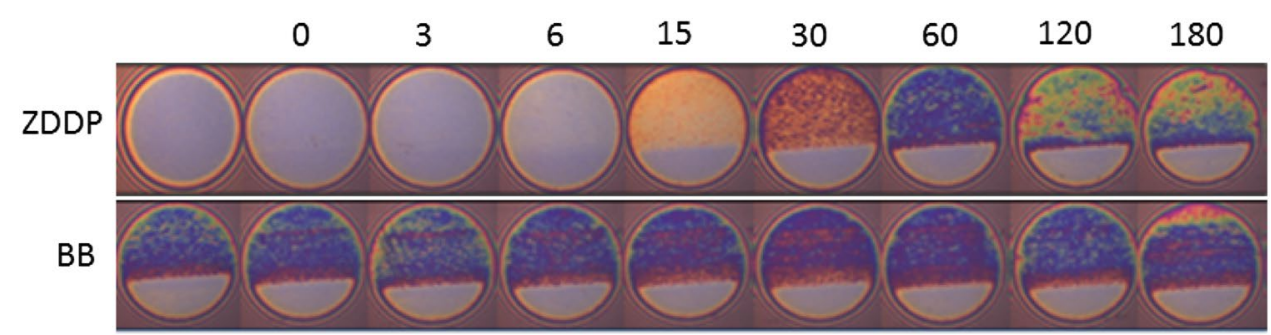


Fig. 7 SLIM images during stage 2 when pre-formed ZDDP film is rubbed for $3 \mathrm{~h}$ in $18 / 12$ solution (upper row) and 18/25 solution (lower row)

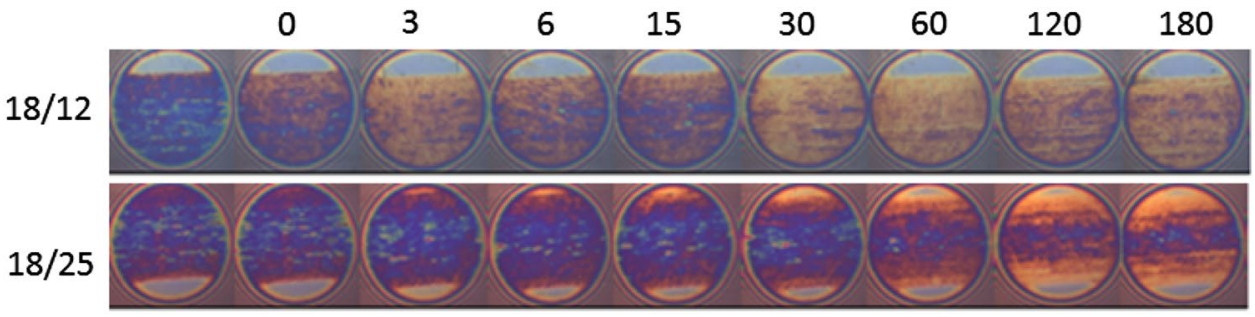

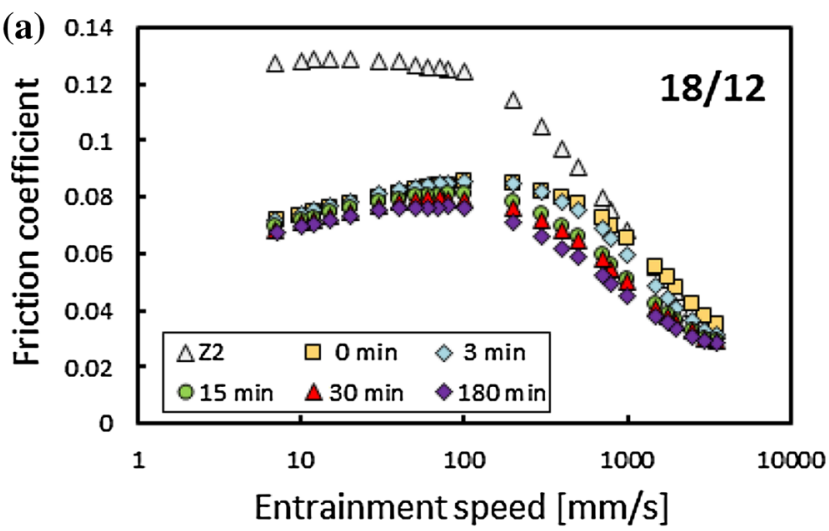

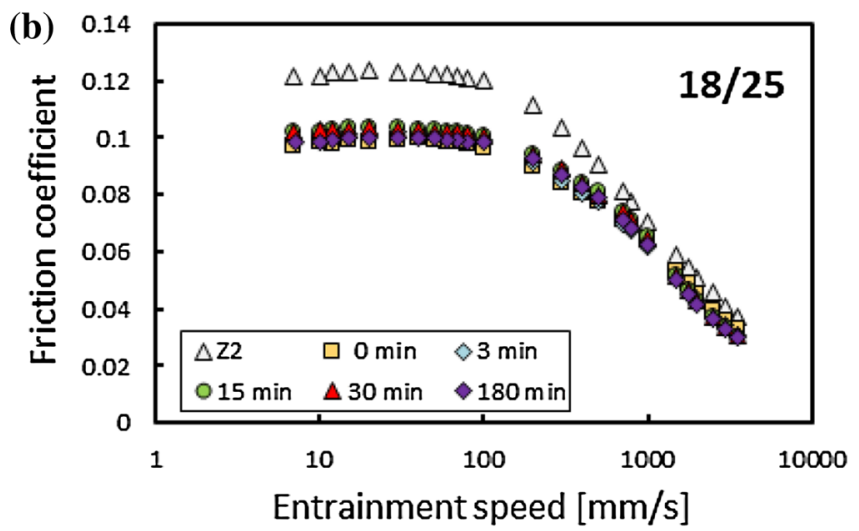

Fig. 8 Stribeck curves obtained during stage 2 for a 18/12 solution; b 18/25 solution

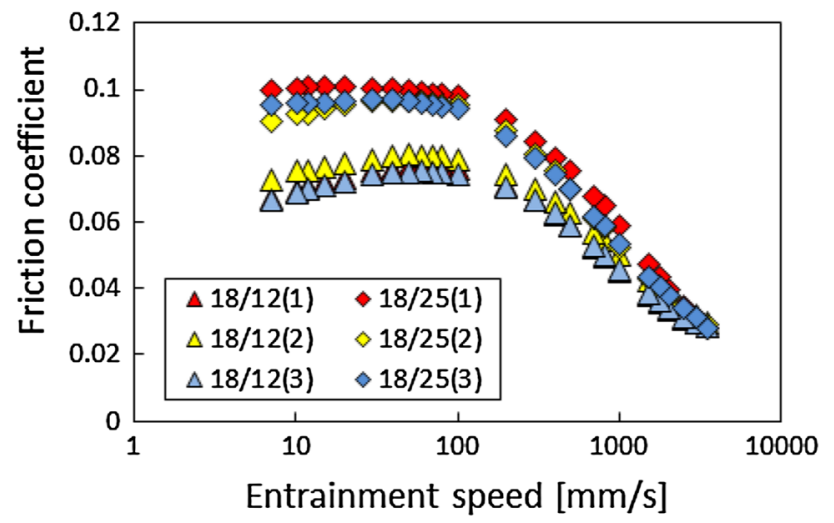

Fig. 9 Stribeck curves obtained at end of stage 2 for three repeat tests using ZDDP solution followed by $18 / 12$ and $18 / 25$ solutions
$18 / 12$ and $18 / 25$. The standard deviations are ca $5 \%$ in the low-speed, boundary lubrication region and demonstrate that the differences between the two OFMs are significant.

Figures 10 and 11 show tribofilm thickness and friction behaviour for stage 2 using $\mathrm{C} / 12$ and $\mathrm{C} / 25$ solutions. Rubbing a ZDDP tribofilm in $\mathrm{C} / 12$ solution results in almost complete loss of the film after $6 \mathrm{~min}$. The film in the central part of the track, where contact pressure is highest, is removed preferentially. By contrast, $\mathrm{C} / 25$ causes little damage to the ZDDP tribofilm. Both OFMs reduce boundary friction. Like 18/12, C/12 results in boundary friction that increases with speed. Unlike 18/25 which gave boundary friction independent of speed, for $\mathrm{C} / 25$ friction does increase with sliding speed. Even more than 18/12, C/12 shows a large reduction of friction in the mixed regime as rubbing progresses and this results from removal of the rough tribofilm-essentially the system is approaching that of the OFM solution with steel surfaces.
Fig. 10 SLIM images during stage 2 when pre-formed ZDDP film is rubbed for $3 \mathrm{~h}$ in $\mathrm{C} / 12$ solution (upper row) and $\mathrm{C} / 25$ solution (lower row)

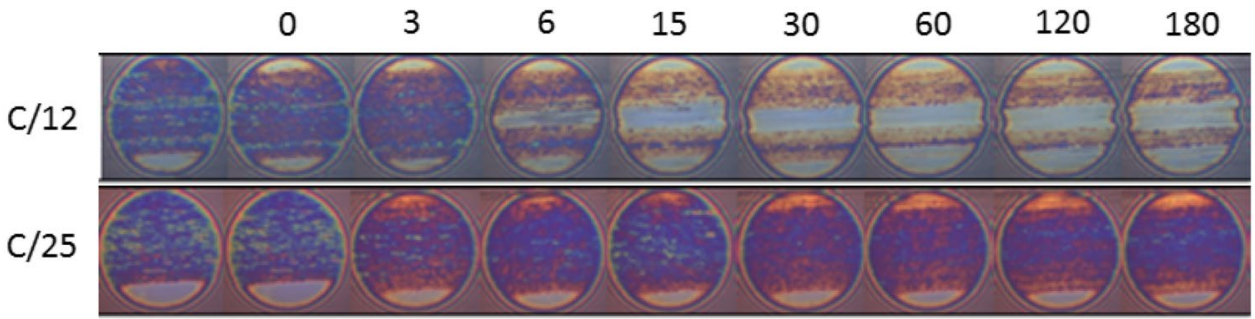



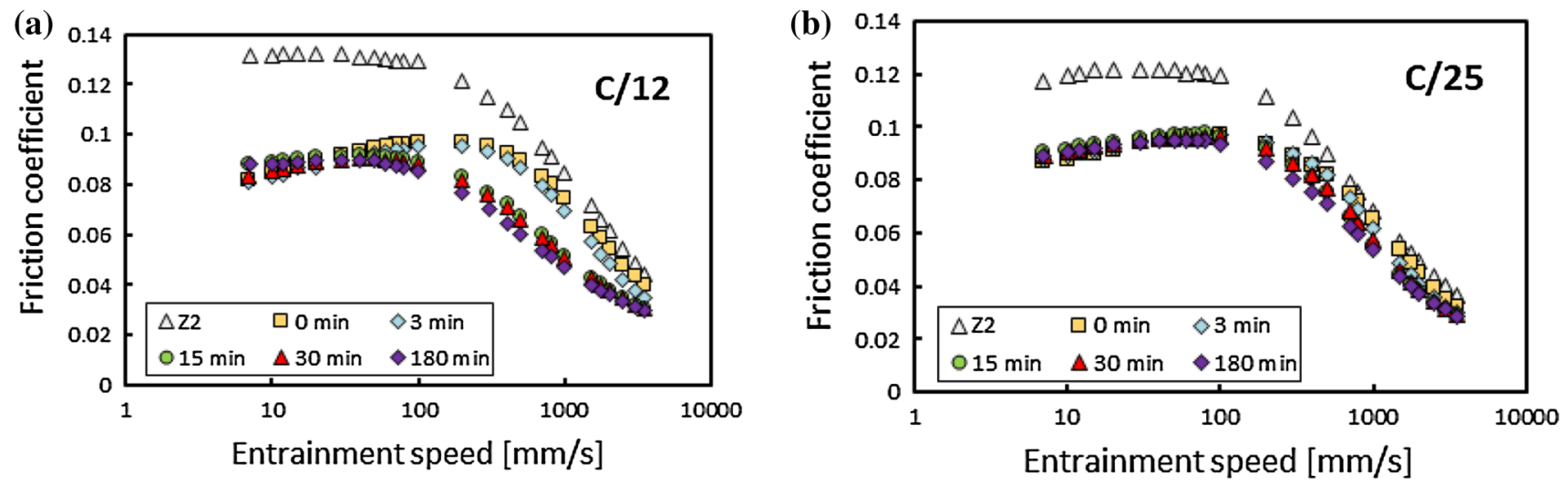

Fig. 11 Stribeck friction curves obtained during stage 2 for a C/12 solution; b C/25 solution

Fig. 12 SLIM images during stage 2 when pre-formed ZDDP film is rubbed for $3 \mathrm{~h}$ in $\mathrm{T} / 12$ solution (upper row) and $\mathrm{T} / 25$ solution (lower row)
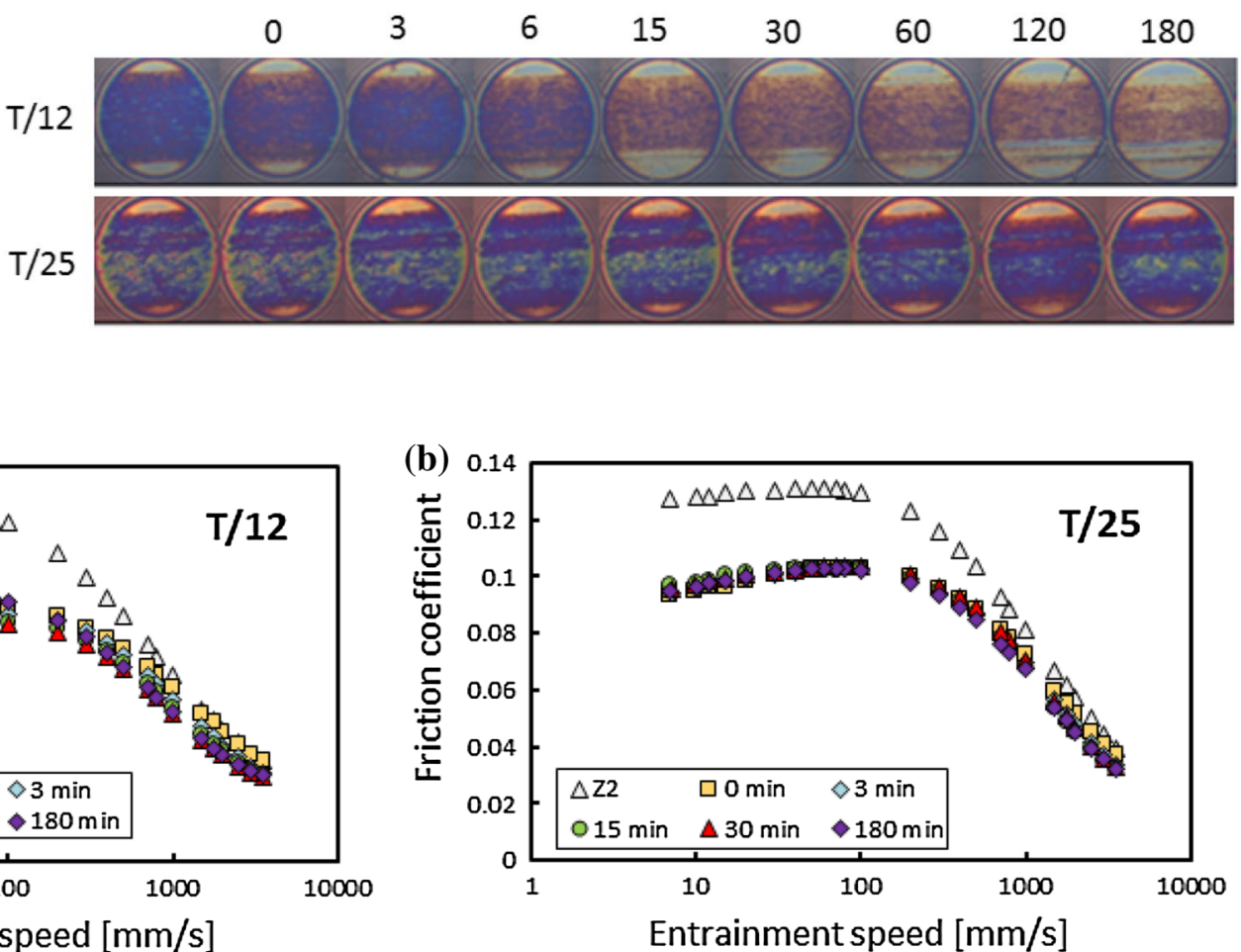

Fig. 13 Stribeck friction curves obtained during stage 2 for a T/12 solution; b T/25 solution

Figures 12 and 13 show results for a ZDDP film rubbed in $\mathrm{T} / 12$ and $\mathrm{T} / 25$ solutions. The tribofilm is partially removed by $\mathrm{T} / 12$, though less than with $\mathrm{C} / 12$ and faster from the sides rather than the centre. Except for additional loss from the sides of the track, the level of film removal is similar to $18 / 12$. Negligible film is removed by $\mathrm{T} / 25$. Like $\mathrm{C} / 12$ and $\mathrm{C} / 25$, boundary friction is immediately reduced on immersion in $\mathrm{T} / 12$ and $\mathrm{T} / 25$ and this friction increases with entrainment speed, and thus, at fixed slide-roll ratio, sliding speed. For $\mathrm{T} / 12$ there is an increase in boundary friction after 3 -h rubbing but, compared to $\mathrm{C} / 12$, there is relatively little reduction in mixed friction, possibly because the film in the central, load-bearing part of the track is not removed and remains rough. For T12, after 30-min rubbing boundary friction increases with rubbing time which may indicate some changes over time in the composition of the adsorbed OFM film.

Figure 14 summarises the influence of rubbing in base blend and in OFM solutions on ZDDP mean tribofilm thickness and root mean square roughness as measured from the discs using AFM after 3-h rubbing. Also shown is the mean thickness of the ZDDP tribofilm before exposure to OFM. 


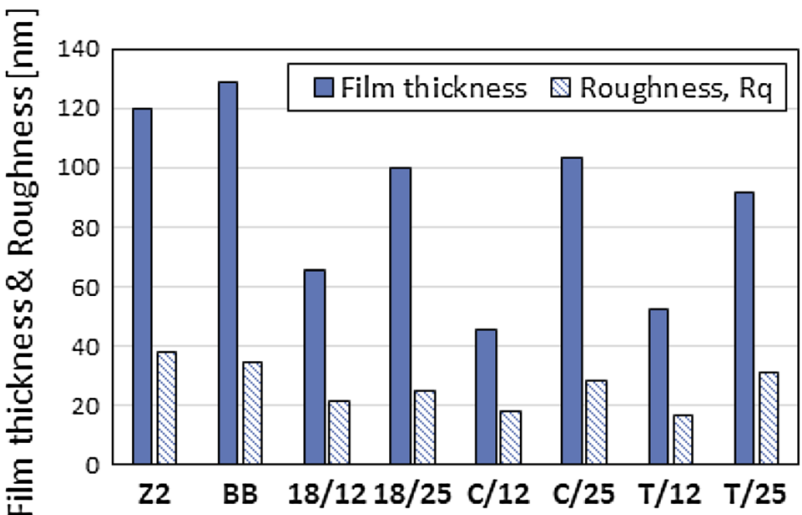

Fig. 14 Change of ZDDP mean tribofilm thickness and roughness after rubbing for $3 \mathrm{~h}$ in stage 2 with BB and various OFM solutions. Measurements made using AFM

The average standard deviation of repeat measurements was between 5 and $6 \%$ for both film thickness and roughness. Rubbing in Ethomeens with 15 ethoxy groups reduces mean tribofilm thickness by about $20-30 \mathrm{~nm}$, while rubbing in Ethomeens with just two ethoxy groups results in about 60 to $80 \mathrm{~nm}$ of the $120 \mathrm{~nm}$ film being lost.

\subsection{OFM Solutions: Wear}

Figure 15 shows the distributions of AFM-measured film thickness over the central third of each film after 3-h rubbing. The unrubbed ZDDP tribofilm in Fig. 15a shows a median thickness of ca $85 \mathrm{~nm}$ but the distribution is skewed so that the mean is higher than this, probably because of the tribofilm pads are flat-topped, while the inter-pad valleys are narrow. As shown in Fig. 15a, ZDDP films after rubbing in the four Ethomeens having just two ethoxy groups all show a marked reduction in film thickness and for $\mathrm{C} / 12$, and to a less extent $\mathrm{T} / 12$, there are some regions that show negative film thickness compared to the reference plane, indicative of wear. By contrast the ZDDP films rubbed in the Ethomeens having 15 ethoxys retain the skewed thickness distribution and there are no regions with negative thickness.

The location of the wear found with some of the Ethomeens can be seen in the SWLI images in Fig. 16. Fig 16a shows a map of film thickness of $\mathrm{C} / 25$ and indicates some localised streaks of wear at the edges of the track but none evident in the central region. This does not prove that there is no wear across the track since the ZDDP film itself might obscure substrate removal. However, removal of the tribofilm with EDTA confirmed that there was no wear within the main part of the rubbed track. By contrast, Figs. 16b and c, which show ZDDP film rubbed in $\mathrm{C} / 12$ and $\mathrm{T} / 12$ solutions, indicate regions where the ZDDP has been completely lost and wear of up to $150 \mathrm{~nm}$ depth has ensued. These regions correspond to those in the SLIM images where the film was fully removed-in the centre of the track for $\mathrm{C} / 12$ but close to the edge for $\mathrm{T} / 12$.

\subsection{Film Composition}

FIB-TEM and XANES were used to examine the impact of one of the OFMs on the composition of the ZDDP tribofilm. Figure 17 shows a high-resolution TEM image of the ZDDP film remaining after rubbing for $3 \mathrm{~h}$ in a solution of 18/12, while Fig. 18 shows a magnified image of part of the film. These indicate that all of the film has a nanocrystalline structure, as also seen with the ZDDP film prior to rubbing in OFM solution [34]. EDX analysis of the FIB wafer shows that the film is comprised predominantly of $\mathrm{O}, \mathrm{P}$ and $\mathrm{Zn}$ with some sulphur in the 30-nm closest to the steel substrate but none further away from the steel surface [37].
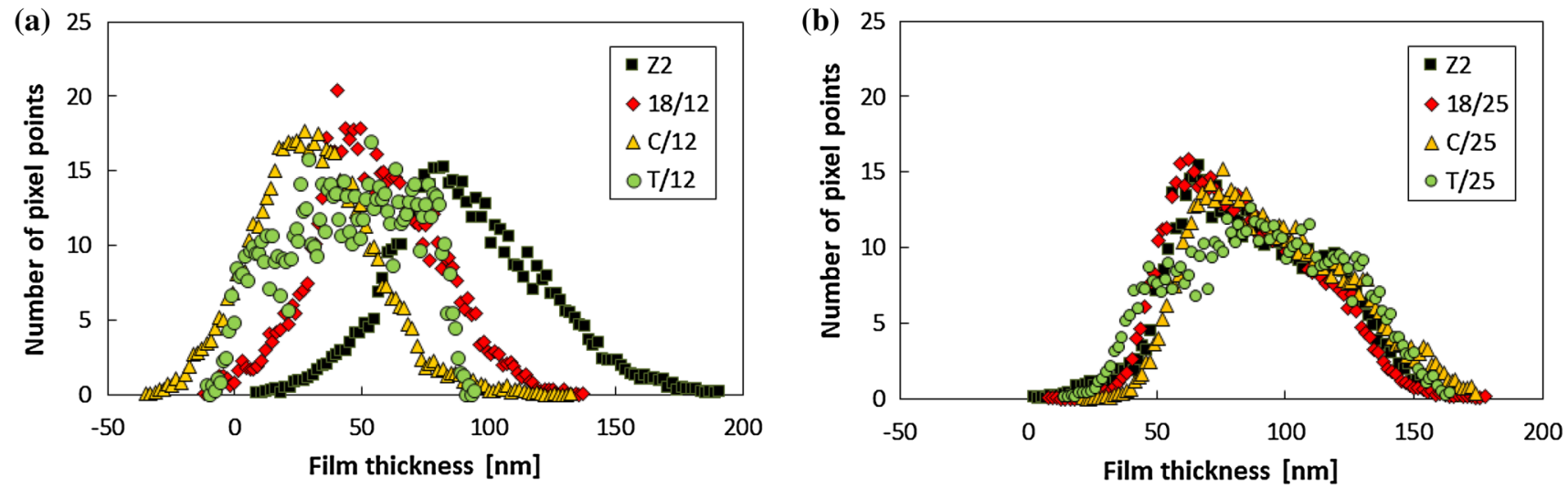

Fig. 15 ZDDP tribofilm thickness distribution on discs after 3-h rubbing in stage 2 in a 18/12, C/12, T/12; b 18/25, C/25, T/25. Also shown are typical distributions after $3 \mathrm{~h}$ rubbing in stage 1 

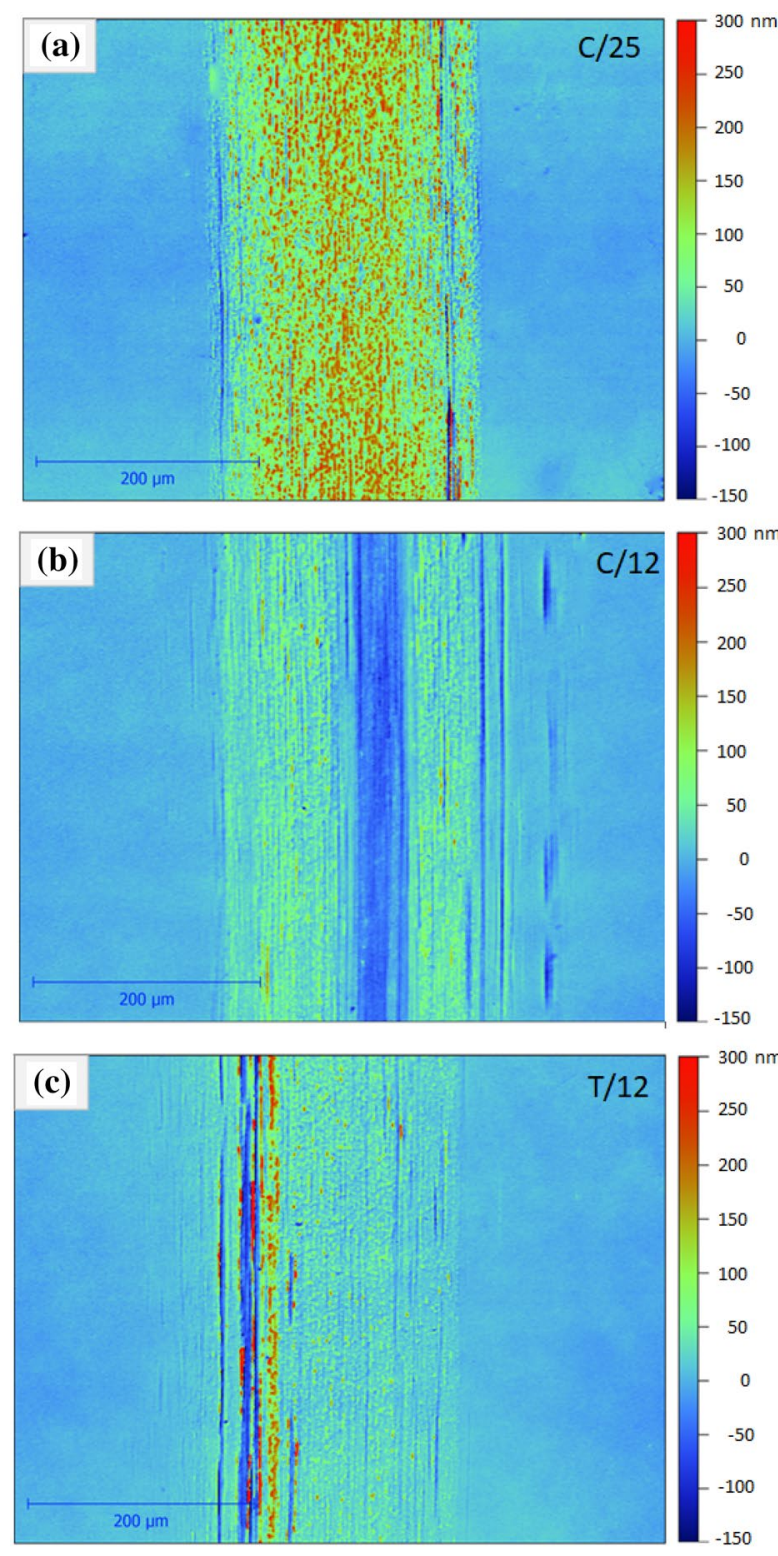

Fig. 16 SWLI images of gold-coated tribofilms on discs after 3-h rubbing in stage 2 with; a C/25 solution, b C/12 solution and $\mathbf{c} \mathrm{T} / 12$ solution

Figure 19 shows the composition of the tribofilm before and after rubbing for $3 \mathrm{~h}$ in 18/12 solution, as determined by XANES. Before rubbing in the Ethomeen solution the measurable part of the film consisted primarily of zinc orthophosphate and no sulphur was resolved. After rubbing in 18/12 solution, the film thickness was reduced to only $65 \mathrm{~nm}$ so that XANES could probe most of this. Again the film consisted primarily of zinc orthophosphate. But iron in the form of iron disulphide was detected by FY in the lowest $60 \mathrm{~nm}$ of the film.

\section{Discussion}

From the above, it can be seen that there are large differences in the influence of the two classes of Ethomeen studied, those with two ethoxy groups and those with 15 ethoxy groups, on ZDDP tribofilm thickness and friction.

It is evident from Figs. 8, 11 and 13 that all the Ethomeens tested produce an immediate and pronounced reduction in friction of ZDDP films and that this persists during three subsequent hours of rubbing. Stribeck curves measured at the start of stage 2 and after 3 -h rubbing are summarised in Fig. 20 for all the solutions tested. From this it can be seen clearly that the friction reduction is consistently greater for the /12 OFMs than the /25 ones, and that for the former the increase of boundary friction with sliding speed is more pronounced. The boundary friction coefficients produced by the /12 OFMs are also more dependent on alkyl group type, with the octadecylbased compounds showing lower friction than the cocoor tallow-derived ones. $18 / 12$ solution shows a decrease in boundary friction with rubbing time, whereas $\mathrm{C} / 12$ and $\mathrm{T} / 12$ show a slight increase in boundary friction after 3-h rubbing. The latter suggests a possible change in the absorbed species on the ZDDP during prolonged rubbing. As expected, there is a drop in mixed friction for all three /12 OFMs after 3-h rubbing, reflecting a reduction in roughness of the ZDDP film as it is partly removed. It should be noted that the initially higher mixed friction of $\mathrm{C} / 12$ solution originates from its initial $\mathrm{Z} 2$ film having somewhat higher mixed friction than those of the other two OFMs, probably reflecting a slightly greater roughness. The friction curves for the three /25 Ethomeens are very similar.

It is of interest to consider the friction results in terms of Ethomeen molecular structures and their consequent ability to form low-friction films. Most striking is the difference between the Ethomeens having two ethoxy groups and those with 15 such groups. With the former there is low friction combined with a pronounced increase in boundary friction with sliding speed. This has been shown experimentally [9] and using molecular dynamics simulation [38] to be indicative of the formation of a relatively close-packed, vertically oriented adsorbed surfactant film, so that sliding occurs predominantly between opposing planes of methyl groups. For saturated linear chain amphiphiles with small head groups such as fatty acids or amines, full close packing is generally considered to occur when each molecule occupies about $0.22 \mathrm{~nm}$, while for unsaturated oleyl-based surfactants a more typical value is $0.44 \mathrm{~nm}^{2}$ [39]. There is very little published, quantitative work on the packing of Ethomeens on solid surfaces from hydrocarbons but 
Fig. 17 TEM image of FIB wafer through ZDDP tribofilm after rubbing in $18 / 12$ solution for $3 \mathrm{~h}$

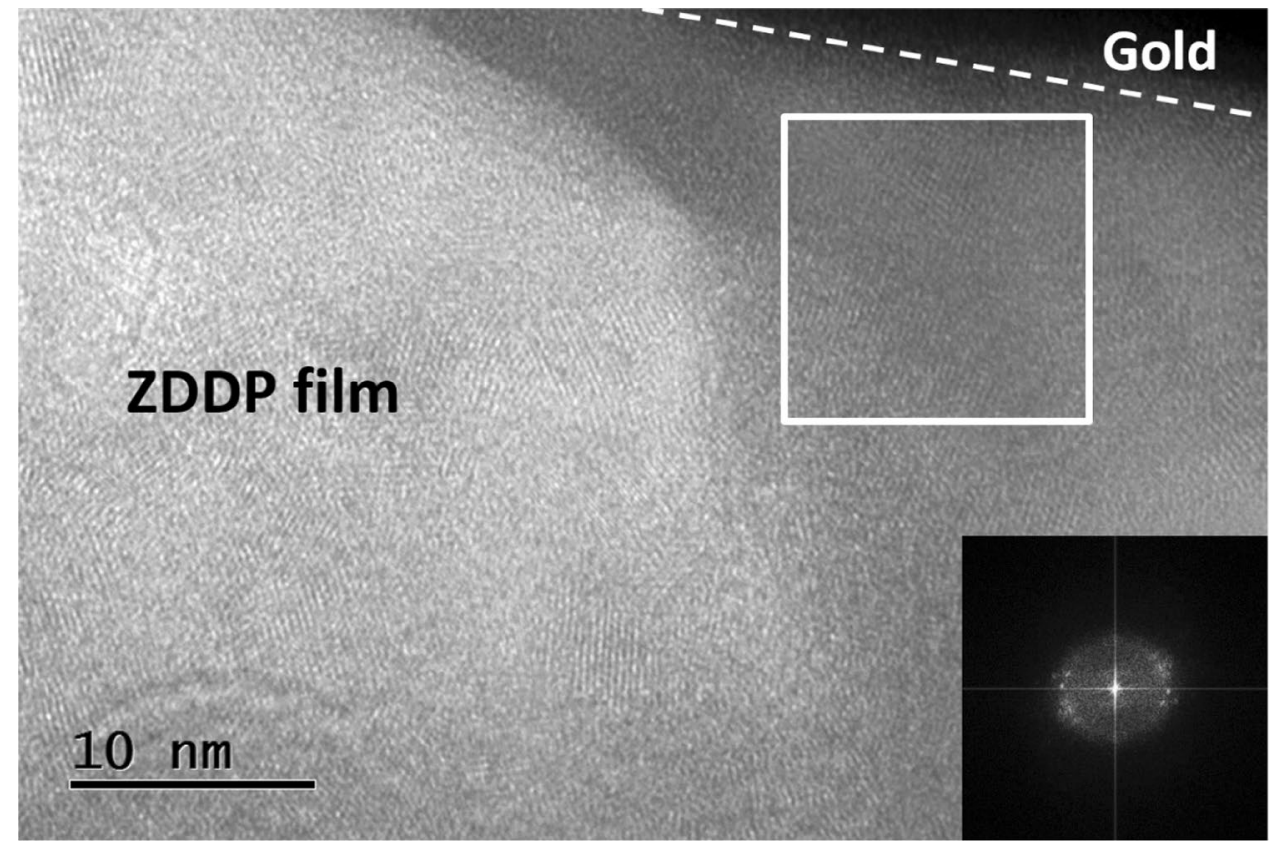

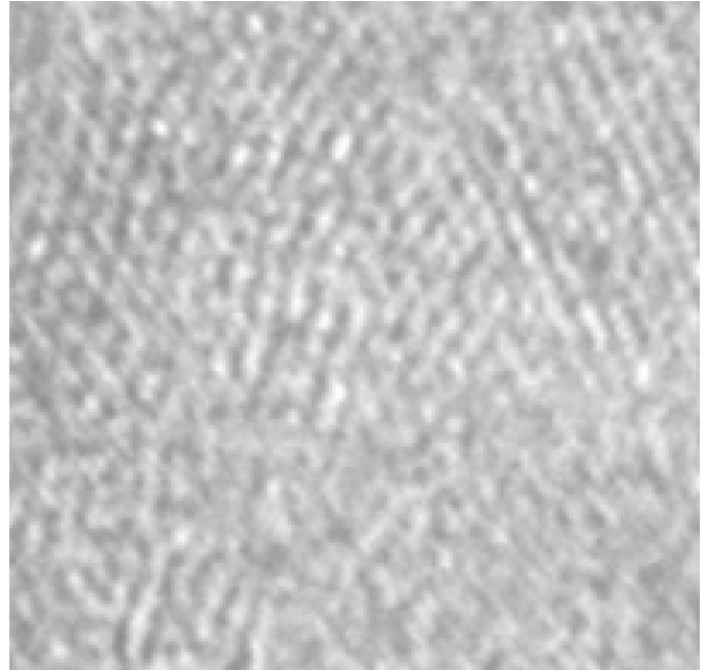

Fig. 18 Magnified region from Fig. 17 to show nanocrystalline structure of film

this will depend on the size of the head group. Based on surface tension measurements, Eriksson suggested that full coverage for an oleyl-based Ethomeen, O/12, lies between a molecular area of $0.45 \mathrm{~nm}^{2}$ and $0.89 \mathrm{~nm}^{2}$, depending on assumptions made concerning screening in the Gibbs equation [25]. It would thus appear that the /12 Ethomeens should be able to form adsorbed monolayers that are reasonably close packed. In the /25 Ethomeens having fifteen ethoxy groups, the ethoxy chains are most likely to be insoluble in the base oil (as is polyethylene glycol) and thus likely to form part of the adsorbing head group. The size of this head group is thus the $\mathrm{N}$ and its two attached ethoxy chains and if these lie adjacent to the tribofilm surface they should occupy an area of ca 4 to $6 \mathrm{~nm}^{2}$. Clearly this precludes close packing of the alkyl chains and this is consistent with the almost sliding speed-independent behaviour observed. It has recently been suggested that even low coverages of an OFM can significantly reduce boundary friction in thinfilm contacts [40]. Closer packing would be possible if the ethoxy chains did not lie adjacent to the substrate, as suggested for glyceryl monooleate at very high coverage [41], but even so, the lengths of the ethoxy chains in the /25 Ethomeens make significant van der Waal interactions between neighbouring alkyl groups unlikely.

There is little difference between the three types of alkyl/ alkenyl group studied except for the slightly lower boundary friction of 18/12 compared to C/12 and T/12. The alkyl groups of the coco- and tallow-based products are actually quite different with coco being predominantly primarily saturated $\mathrm{C} 12$ and tallow predominantly saturated and unsaturated $\mathrm{C} 16$ and $\mathrm{C} 18$ but these differences are not strongly reflected in friction reduction performance.

FIB-TEM and XANES of the tribofilm before and after rubbing in OFM indicated that the initial film was mainly zinc orthophosphate and that some of this was removed by rubbing in OFM. This was somewhat unexpected, especially with analysis using L-edge TEY which probes the immediate surface, since a number of XPS studies have shown a high proportion of polyphosphate in the near surface of ZDDP tribofilms [42]. Two possible reasons for the absence of measureable polyphosphate are as follows. One is that the ZDDP tribofilm formation stage 1 was quite long in this work, at 3-h rubbing. A number of studies have found that 
Fig. 19 Schematic diagram of ZDDP film revealed by XANES analysis before (left) and after (right) rubbing in 18/12 solution for $3 \mathrm{~h}$

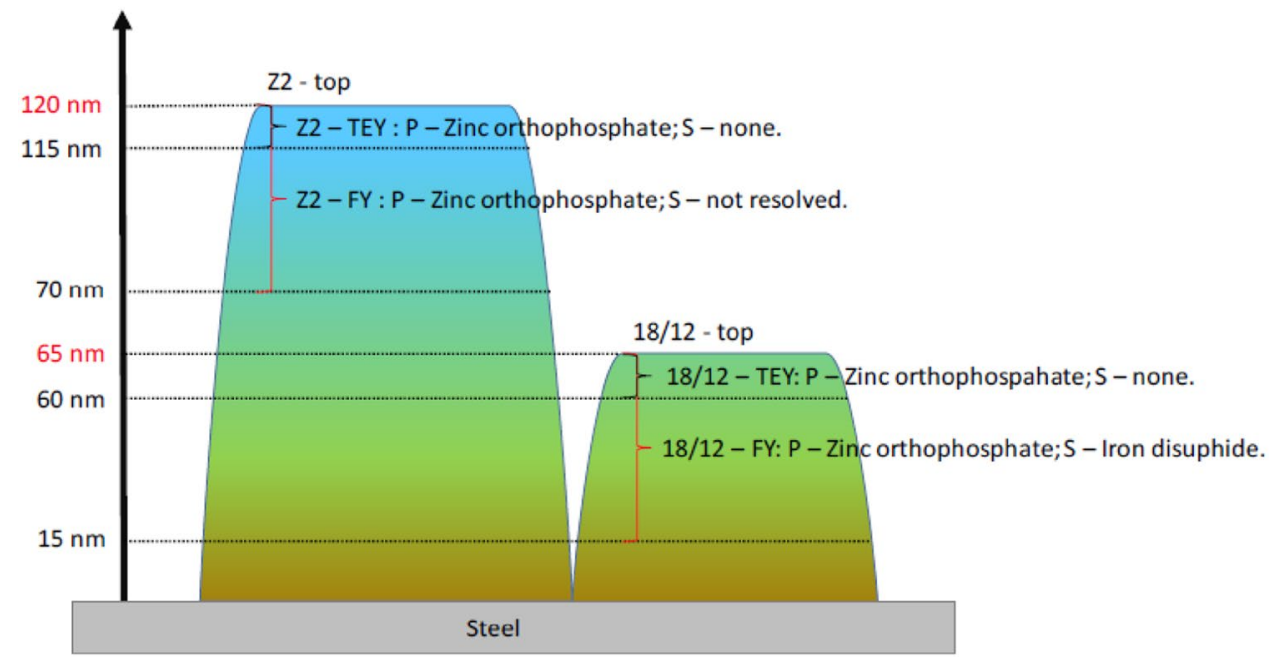

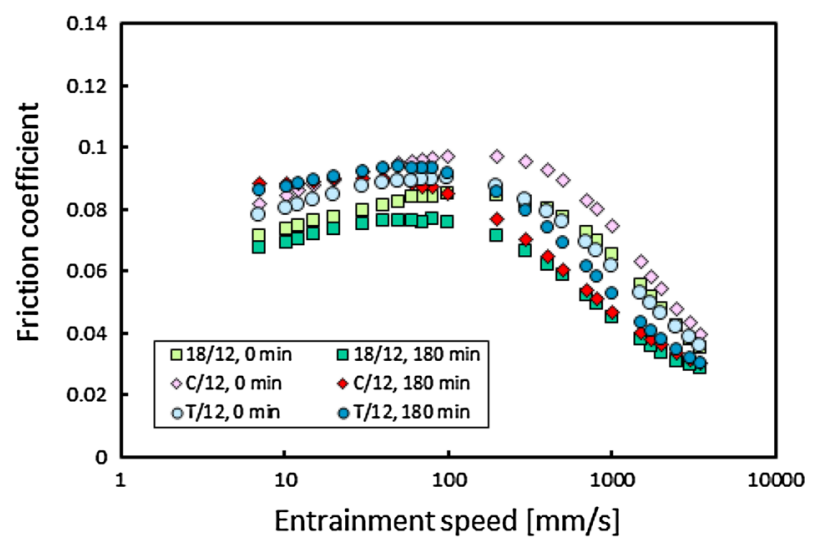

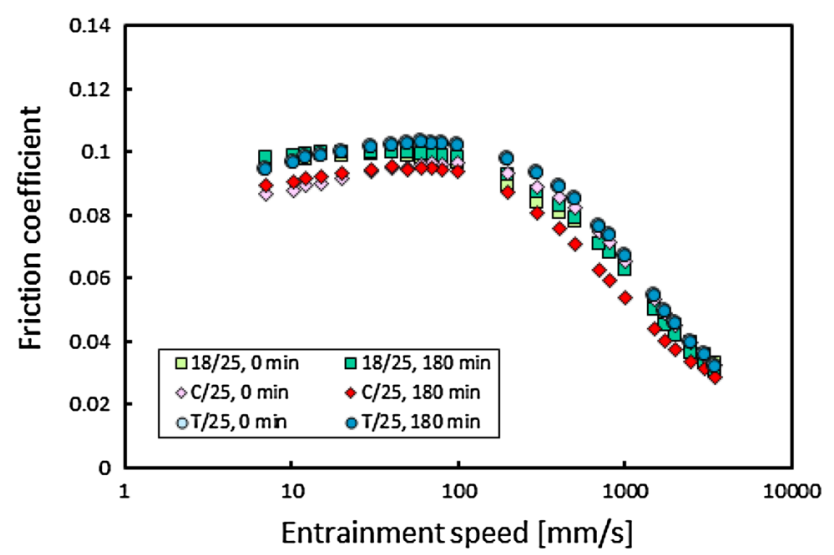

Fig. 20 Stribeck friction curves of the /12 and /25 OFMs at the beginning and end of stage 2 tests

ZDDP tribofilms gradually transform from polyphosphate to short-chain phosphate during extended rubbing [42, 43] and it is thus quite likely that most of the tribofilm formed in the current study was, in fact depolymerised orthophosphate. Concerning the immediate surface where polyphosphate might be expected to be most likely to be present, this may have been removed by cleaning. Prior to FIB, the discs were cleaned in an ultrasonic bath in toluene for $15 \mathrm{~min}$ to remove all volatiles and this might have also removed the more fragile polyphosphate from the surface, or, indeed depolymerised it.

\section{Conclusions}

The influence of a series of Ethomeens (ethoxylated alkylamines) on the durability and friction of tribofilms formed by a commercial blend of primary and secondary ZDDP in sliding/rolling contact has been studied. FIB-TEM and XANES analysis shows that the ZDDP tribofilms, which are formed during 3-h rubbing at $100{ }^{\circ} \mathrm{C}$, have a nanocrystalline structure and consist principally of zinc orthophosphate, with some iron disulphide in regions close to the steel substrate.

When the pre-formed tribofilms are rubbed in Ethomeen solution, boundary friction is reduced and some of the ZDDP film is removed. Ethomeens having just two ethoxy groups give lower boundary friction on ZDDP than those with fifteen ethoxy groups, but result in much greater removal of the tribofilm itself. When ZDDP tribofilms are rubbed in Ethomeens having 15 ethoxy groups only about $20 \mathrm{~nm}$ of the initial $120 \mathrm{~nm}$ of film is lost and negligible wear is observed in a 3-h test. By contrast, when ZDDP tribofilms are rubbed in solutions of Ethomeens having two ethoxy groups, typically about half the film thickness being lost and wear of the steel substrate occurs. Based on XANES analysis, the film removed by Ethomeens is thus primarily orthophosphate.

The level of boundary friction and its dependence on sliding speed, coupled with the dimensions of the molecules, suggests that the Ethomeens with two ethoxy groups may 
form quite closely packed vertical monolayers on ZDDP tribofilm surfaces, but that those with fifteen ethoxy groups cannot be close packed, though they still reduce boundary friction significantly.

The study shows that selection of an appropriate aminic friction modifier for use with ZDDP is a balance between its ability to reduce friction and its potentially harmful effect on a ZDDP tribofilm. Although only one ZDDP was studied, the finding should be applicable to all alkyl ZDDPs. This means that despite their apparent inability to form close-packed monolayer films, the additives having longer polyethoxy chains may be more suited to use with ZDDPs than those with just 2 ethoxy groups. Since hindered tertiary amines show considerable promise as organic friction modifiers for engine oils, this study should assist in the formulation of lubricants and fuels giving low boundary friction and thus improved fuel economy.

Acknowledgements The authors wish to acknowledge the support of Shell via the Shell University Technology Centre (UTC) for Fuels and Lubricants at Imperial College. They would also like to thank Dr Rossi of ETH for providing zinc polyphosphate reference samples, the Canadian Light Source for access to synchrotron facilities in Saskatoon, Canada and Lucia Zuin for her valuable help in analysing XANES data.

Open Access This article is distributed under the terms of the Creative Commons Attribution 4.0 International License (http://creativeco mmons.org/licenses/by/4.0/), which permits unrestricted use, distribution, and reproduction in any medium, provided you give appropriate credit to the original author(s) and the source, provide a link to the Creative Commons license, and indicate if changes were made.

\section{References}

1. Kennedy, S., Moore, L.D.: Additive effects on lubricant fuel economy. SAE Trans. 96, 681-691 (1987)

2. Bovington, C., Anghel, V., Spikes, H.A.: Predicting sequence VI and VIA fuel economy from laboratory bench tests. SAE Techn. Paper 961142 (1996)

3. Topolovec-Miklozic, K., Forbus, T.R., Spikes, H.A.: Performance of friction modifiers on ZDDP-generated surfaces. Trib. Trans. 50, 328-335 (2007)

4. Waddey, W.E., Shaub, H., Pecoraro, J.M, Carley, R.A.: Improved fuel economy via engine oils. SAE Techn. Paper 78059 (1978)

5. Tripaldi, G., Vettor, A., Spikes, H.A.: Friction behaviour of ZDDP films in the mixed boundary/EHD regime. SAE Tech. Paper 962036 (1996)

6. Dawczyk, J., Morgan, N., Russo, J., Spikes, H.A.: ZDDP tribofilm in rolling-sliding contact. Tribol. Lett. 67, 34 (2019)

7. Aoki, S., Suzuki, A., Masuko, M.: Comparison of sliding speed dependency of friction between steel surfaces lubricated with several ZnDTPs with different hydrocarbon moieties. Proc. Inst. Mech. Eng. J220, 343-351 (2006)

8. Hoshino, K., Yagashita, K., Tagawa, K., Spikes, H.A.: Tribological properties of sulphur-free antiwear additives zinc dialkylphosphates (ZDPs). SAE Int. J. Fuels Lubr. 5, 504-510 (2012)

9. Campen, S., Green, J.H., Lamb, G.D., Atkinson, D., Spikes, H.A.: On the increase in boundary friction with sliding speed. Tribol. Lett. 48, 237-248 (2012)
10. Rounds, F.: Effects of organic molybdenum compounds on the friction and wear observed with ZDP-containing lubricant blends. Trib. Trans. 3, 345-354 (1990)

11. Stipanovic, A.J., Schoonmaker, J.P.: The impact of organomolybdenum compounds on the frictional characteristics of crankcase engine oils. SAE Techn. Paper 932779 (1993)

12. Muraki, M., Yanagi, Y., Sakaguchi, K.: Synergistic effect on frictional characteristics under rolling-sliding conditions due to a combination of molybdenum dialkyldithiocarbamate and zinc dialkyldithiophosphate. Trib. Intern. 30, 69-75 (1997)

13. Korcek, S., Jensen, R.K., Johnson, M.D.: Interactions leading to formation of low friction films in systems containing molybdenum dialkyldithiocarbamate and zinc dialkyldithiophosphate additives. In: Dowson, D., et. al. (eds.) Proc. Leeds-Lyon Symp. Thinning Films and Tribological Interfaces, pp. 399-407. Elsevier, Amsterdam (2000)

14. Graham, J., Spikes, H., Jensen, R.: The friction reducing properties of molybdenum dialkyldithiocarbamate additives: Part IIdurability of friction reducing capability. Trib. Trans. 44, 637-647 (2001)

15. Bec, S., Tonck, A., Georges, J.-M., Roper, G.W.: Synergistic effects of MoDTC and ZDTP on frictional behaviour of tribofilms at the nanometer scale. Tribol. Lett. 17, 797-809 (2004)

16. Ye, J., Araki, S., Kano, M., Yasuda, Y.: Nanometer-scale mechani$\mathrm{cal} /$ structural properties of molybdenum dithiocarbamate and zinc dialkylsithiophosphate tribofilms and friction reduction mechanism. Jpn. J. Appl. Phys. 44, 5358-5361 (2005)

17. Morina, A., Neville, A., Priest, M., Green, J.H.: ZDDP and MoDTC interactions in boundary lubrication-the effect of temperature and ZDDP/MoDTC ratio. Trib. Int. 39, 1545-1557 (2006)

18. Papay, A.G., O'Brien, J.P.: Lubricating and fuel compositions containing succinimide friction reducers. US Patent 4,237,020 (1980)

19. Zaweski, E.F. (inventor): Ethyl Corp, assignee: improved crankcase lubricant composition. US Patent 4,208,293 (1980)

20. Wisotsky, M.J.: Lubricating oil compositions containing hydroxamide compounds as friction reducers. US Patent 4,557,846 (1985)

21. Brewster, P.W., Smith, C.R., Gowland, F.W.: Glycerol esters as fuel economy additives. US Patent 4,683,069 (1987)

22. Scanlon, E., Hayden, T., Jung, A., Hoey, M.: Alkoxylated amides, esters, and anti-wear agents in lubricant compositions. US Patent 9,909,081 (2018)

23. Ratoi, M., Niste, V.B., Alghawel, H., Suen, Y.F., Nelson, K.: The impact of organic friction modifiers on engine oil tribofilms. RSC Adv. 4, 4278-4285 (2014)

24. Dobrenizki, L., Tremmel, S., Wartzack, S., Hoffmann, D.C., Brögelmann, T., Bobzin, K., Bagcivan, N., Musayev, Y., Hosenfeldt, T.: Efficiency improvement in automobile bucket tappet/ camshaft contacts by DLC coatings-influence of engine oil, temperature and camshaft speed. Surf. Coat. Technol. 308, 360-373 (2016)

25. Eriksson, K.: Fatty amines as friction modifiers in engine oils: correlating adsorbed amount to friction and wear performance. Master's thesis, Chalmers University of Technology, Gothenburg, Sweden (2014)

26. Lundgren, S.M., Eriksson, K., Rossenaar, B.: Boosting the friction performance of amine friction modifiers with MoDTC. SAE Int. J. Fuels Lubr. 8, 27-30 (2015)

27. Akzo Nobel General Catalogue.: https://vdocuments.site/akzonobel-general-catalog.html

28. Cann, P.M., Hutchinson, J., Spikes, H.A.: The development of a spacer layer imaging method (SLIM) for mapping elastohydrodynamic contacts. Trib. Trans. 39, 915-921 (1996)

29. Fujita, H., Spikes, H.A.: Formation of zinc dithiophosphate antiwear films. Proc. I. Mech. E. J218, 265-277 (2004) 
30. Chittenden, R.J., Dowson, D., Dunn, J.F., Taylor, C.M.: A theoretical analysis of the isothermal elastohydrodynamic lubrication of concentrated contacts. I. Direction of lubricant entrainment coincident with the major axis of the Hertzian contact ellipse. Proc. R. Soc. Lond. 397, 245-269 (1985)

31. Spikes, H.A.: Basics of EHL for practical application. Lubr. Sci. 27, 45-67 (2015)

32. Topolovec-Miklozic, K., Forbus, T.R., Spikes, H.A.: Film thickness and roughness of ZDDP antiwear films. Tribol. Lett. 26, 161-171 (2007)

33. Benedet, J., Green, J.H., Lamb, G.D., Spikes, H.A.: Spurious mild wear measurement using white light interference microscopy in the presence of antiwear films. Trib. Trans. 52, 841-846 (2009)

34. Dawczyk, J., Ware, E., Ardakani, M., Russo, J., Spikes, H.A.: Use of FIB to study ZDDP tribofilms. Tribol. Lett. 66, 155 (2018)

35. ATHENA: XAS DataProcessing. http://bruceravel.github.io/ demeter/documents/Athena/index.html

36. De Barros, M.I., Bouchet, J., Raoult, I., Le Mogne, T., Martin, J.M.: Friction reduction by metal sulfides in boundary lubrication studied by XPS and XANES analysis. Wear 254, 863-870 (2003)

37. Dawczyk, J.U.: The effect of organic friction modifiers on ZDDP tribofilm. PhD thesis, Imperial College London (2018)

38. Ewen, J.P., Gattinoni, C., Morgan, N., Spikes, H.A., Dini, D.: Non-equilibrium atomistic simulations of organic friction modifiers adsorbed on iron-oxide surfaces. Langmuir 32, 4450-4463 (2016)
39. Benerito, R.R., Singleton, W.S.: Fat emulsion. Effect of heat on solubility of hydrophilic emulsifiers. J. Am. Oil Chem. Soc. 33, 364-367 (1956)

40. Jaishankar, A., Jusufi, A., Vreeland, J.L., Deighton, S., Pellettiere, J., Schilowitz, A.M.: Adsorption of stearic acid at the iron oxide/ oil interface: theory, experiments, and modeling. Langmuir 35, 2033-2046 (2019)

41. Gattinoni, C., Ewen, J.P., Dini, D.: Adsorption of surfactants on $\alpha-\mathrm{Fe}_{2} \mathrm{O}_{3}(0001)$ : a density functional theory study. J. Phys. Chem. C 122, 20817-20826 (2018)

42. Heuberger, R., Rossi, A., Spencer, N.D.: XPS study of the influence of temperature on ZnDTP tribofilm composition. Tribol. Lett. 25, 185-196 (2007)

43. Parsaeian, P., Ghanbarzadeh, A., Van Eijk, M.C., Nedelcu, I., Neville, A., Morina, A.: A new insight into the interfacial mechanisms of the tribofilm formed by zinc dialkyl dithiophosphate. Appl. Surf. Sci. 403, 472-486 (2017)

Publisher's Note Springer Nature remains neutral with regard to jurisdictional claims in published maps and institutional affiliations. 